\title{
A Pattern Language for High-Performance Computing Resilience
}

\author{
Saurabh Hukerikar and Christian Engelmann, Oak Ridge National Laboratory
}

\begin{abstract}
High-performance computing systems (HPC) provide powerful capabilities for modeling, simulation, and data analytics for a broad class of computational problems. They enable extreme performance of the order of quadrillion floating-point arithmetic calculations per second by aggregating the power of millions of compute, memory, networking and storage components. With the rapidly growing scale and complexity of HPC systems for achieving even greater performance, ensuring their reliable operation in the face of system degradations and failures is a critical challenge. System fault events often lead the scientific applications to produce incorrect results, or may even cause their untimely termination. The sheer number of components in modern extreme-scale HPC systems and the complex interactions and dependencies among the hardware and software components, the applications, and the physical environment makes the design of practical solutions that support fault resilience a complex undertaking. To manage this complexity, we developed a methodology for designing HPC resilience solutions using design patterns. We codified the well-known techniques for handling faults, errors and failures that have been devised, applied and improved upon over the past three decades in the form of design patterns. In this paper, we present a pattern language to enable a structured approach to the development of HPC resilience solutions. The pattern language reveals the relations among the resilience patterns and provides the means to explore alternative techniques for handling a specific fault model that may have different efficiency and complexity characteristics. Using the pattern language enables the design and implementation of comprehensive resilience solutions as a set of interconnected resilience patterns that can be instantiated across layers of the system stack.
\end{abstract}

CCS Concepts: •Software and its engineering $\rightarrow$ Patterns; Designing software; Software fault tolerance;

Additional Key Words and Phrases: High-Performance Computing, Resilience, Fault Tolerance, Design Patterns

ACM Reference Format:

Saurabh Hukerikar, Christian Engelmann. 2017. A Pattern Language for High-Performance Computing Resilience EuroPLoP (July 2017), 16 pages.

DOI : $10.1145 / 3147704.3147718$

This work was sponsored by the U.S. Department of Energy's Office of Advanced Scientific Computing Research. This manuscript has been authored by UT-Battelle, LLC under Contract No. DE-AC05-00OR22725 with the U.S. Department of Energy. The United States Government retains and the publisher, by accepting the article for publication, acknowledges that the United States Government retains a non-exclusive, paid-up, irrevocable, world-wide license to publish or reproduce the published form of this manuscript, or allow others to do so, for United States Government purposes. The Department of Energy will provide public access to these results of federally sponsored research in accordance with the DOE Public Access Plan (http://energy.gov/downloads/doe-public-access-plan).

Publication rights licensed to ACM. ACM acknowledges that this contribution was authored or co-authored by an employee, contractor or affiliate of the United States government. As such, the Government retains a nonexclusive, royalty-free right to publish or reproduce this article, or to allow others to do so, for Government purposes only.

EuroPLoP' 17, July 12-16, 2017, Irsee, Germany

(C) 2017 Copyright held by the owner/author(s). Publication rights licensed to ACM.

ACM ISBN 978-1-4503-4848-5/17/07...\$15.00

https://doi.org/10.1145/10.1145/3147704.3147718 


\section{INTRODUCTION}

High-performance computing (HPC) systems, through a combination of massively parallel processing capability and storage capacity, can rapidly solve difficult computational problems in a diverse range of scientific and engineering domains. The design of faster and higher capability HPC systems make significant contributions to scientific progress by providing researchers with capabilities for advanced simulation, computational, mathematical and statistical modeling, visualization and data analytics. HPC systems are specialized, custom-built machines that are constructed through aggregation of the compute, memory and storage capabilities of hundreds of thousands of components. A typical highperformance computing system contains thousands of processors, several terabytes of memory, and petabytes of storage, and requires highly-customized power and cooling infrastructure. The current generation of HPC systems are capable of performing over a quadrillion $\left(10^{15}\right)$ floating-point arithmetic operations per second. Yet, there is a significant push by the HPC community to design and deploy next generation of systems that will be capable of exaflops performance ( $10^{18}$ operations per second) [Dongarra et al. 2011] in order to enable higher fidelity simulation and predictive analysis capabilities.

To design, build and effectively operate next-generation exascale-class HPC systems, which will be at least 100 times more capable than the fastest systems today, there are several key challenges that must be addressed [Kogge et al. 2008]. Many of these challenges arise from the need to employ hundreds of millions of processing, memory and storage components, and a complex multicomponent software environment to achieve orders of magnitude greater computational performance. In addition to the management of unprecedented levels of parallelism, reducing power consumption and coping with an exponentially higher rate of system faults are significant challenges for future HPC system environments.

The challenge of maintaining fault resilient operation is particularly difficult in emerging system architectures that employ hundreds of millions of processing, memory and storage components, and a complex multicomponent software environment, which makes the timely identification and correction of errors much more difficult [DeBardeleben et al. 2009]. For long-running simulation, modeling and analysis applications that run on HPC systems, the frequent occurrence of faults may cause incorrect outcomes, or may even lead to fatal crashes of the application program. Therefore, effective resilience solutions that keep HPC applications running to a correct solution in spite of frequent faults will be indispensable for future HPC systems and their applications.

Solving the resilience problem for extreme-scale HPC systems is a complex undertaking given the growing hardware and software complexity of HPC environments and the emergence of new fault modes at accelerated rates. Many of the existing resilience solutions will prove to be insufficient and some will no longer be viable in future systems unless they are significantly reengineered [Elnozahy et al. 2010]. These challenges are elaborated in Section 2. To address the resilience challenge, we developed design patterns, which describe the best-known techniques that have been devised and repeatedly applied to confront different types faults, and the resulting errors and failures, in the context of HPC environments over the past three decades [Hukerikar and Engelmann 2017]. The techniques have been formatted as patterns and organized by a hierarchical classification scheme to serve as a resource for designers to draw upon when designing HPC resilience solutions [Hukerikar and Engelmann 2016]. The design pattern specification describes the detailed descriptions for detection, containment and mitigation of faults, errors and failures that occur in the context of HPC environments. Section 3 summarizes the various resilience design patterns and Section 4 presents a classification scheme. This paper presents a pattern language for the design and implementation of complete, working HPC resilience solutions. The pattern language, which is introduced in Section 5, codifies how the patterns are related to each other. Using the resilience patterns as its elements, the language defines 
the discipline that makes it possible to combine the individual patterns to create functional resilience solutions. The language enables exploration of pattern-based solutions that have different efficiency and complexity characteristics, and guides a designer from the beginning of a design problem to the successful realization of its solution. Our pattern language is extremely practical, allowing designers to integrate patterns across the system stack. This pattern language is designed to be useful for HPC hardware and software designers, including system architects, the software developers who implement the libraries and applications for HPC applications, system users and operators.

\section{THE HIGH-PERFORMANCE COMPUTING RESILIENCE CHALLENGE}

\subsection{Terminology}

Most modern high-performance computing systems are distributed-memory systems that are architected as clusters. They consist of nodes, each of which contains processors, memory, and runs its own instance of an operating system. The nodes are connected to each other using high-speed networks. Each node is a shared-memory system consisting of one or more multicore processors; newer node architectures also contain one of more graphical processing units (GPU). Parallel applications distribute their data or tasks across multiple compute nodes to accomplish its work faster. The software environment includes runtimes system frameworks for scheduling, memory management, communication frameworks, performance monitoring tools, numerical libraries, compiler tools, which support and optimize the execution of the parallel application programs. The workload of HPC systems consists of scientific and engineering simulation, modeling and analysis programs, that use message passing for exchange of data between processes and synchronization. Therefore, in the context of cluster-based HPC systems, and for the purpose of discussing design patterns for such systems, the term system refers to an entity that has the notion of a well-defined structure and behavior. A subsystem is a set of elements, which is a system itself, and is a component of a larger system, i.e., a system is composed of multiple sub-systems or components. For example, the term system may be used to refer to compute nodes, I/O nodes, network interfaces, disks, etc., or in the software it may be used to refer to a library, runtime framework, or even a function or a variable in a program. The term full system refers to the HPC system as a whole, or to a collection of nodes that is capable of running a parallel application.

In fault tolerance literature, the terms fault, error, or failure have specific meanings. A fault is an underlying flaw or defect in a system that has potential to cause problems. A fault can be dormant and can have no effect. When activated during system operation, a fault leads to an error; an error event results from the activation of a fault and cause an illegal system state; and a failure occurs if an error reaches the service interface of a system, resulting in system behavior that is inconsistent with the system's specification.

\subsection{Need for Resilience in High Performance Computing Systems}

HPC systems are built using a very large number of nodes each consisting of many processor, memory, network and storage components. With a very large number of aggregate hardware components, the system-level probability that one of them fails is significantly higher. Furthermore, the workload of HPC systems consists of parallel application programs written in languages such as C, C++, Fortran that use a model of message passing between processes. Often the applications use a library implementation of the Message Passing Interface (MPI). However, this flat model of message passing offers no containment for errors or failures; an error in the state of any MPI process may spread to affect the state of processes on other nodes in the system. Similarly, the failure of any one MPI process causes the remaining communicating processes to block indefinitely, which prevents the parallel application from resuming execution. The large number of nodes in cluster-based HPC systems with massive number 
of hardware components and the prevalence of a message-passing-based programming model with inherent failure containment and recovery capabilities, makes resilience an indispensable capability for HPC systems. Resilience solutions are based on a collection of techniques for keeping HPC applications running to a correct solution in a timely and efficient manner despite underlying system faults, errors and failures.

\subsection{Resilience at Extreme Scale}

In recent years, the progress in the computing capabilities of HPC systems is primarily driven by increasing the number of compute, memory and storage components. These components consist of VLSI chips that are constructed using transistor devices, whose geometries are shrunk every semiconductor process technology generation. As process technology scales further, VLSI devices face new challenges, such as variability, single-event upsets, decreased noise immunity due to NTV operation, transistor device degradation. These effects manifest themselves as unreliable behavior of the components in an HPC system. In addition to this disturbing trend is the rapidly growing scale and complexity of the hardware and software architecture of modern HPC systems, which makes management of reliability of the system a difficult challenge. The timely detection of faults and degradations, limiting their propagation in the multicomponent system environment, and handling the resulting errors and failures gracefully and efficiently is a daunting challenge for highly-complex, future extreme-scale HPC systems.

\section{RESILIENCE DESIGN PATTERNS}

A resilience solution in a hardware or software component in an HPC system is based on taking appropriate action in the event of a fault, error, or failure. Many of the techniques for confronting these events that have been devised, applied and improved over the past three decades represent general solutions to recurring problems in the design of resilience solutions for high-performance computing systems. We presented some of these well-known techniques, formatted as resilience design patterns [Hukerikar and Engelmann 2017].

Our effort was motivated by the fact that there are a number of hardware and software-based technologies used in HPC systems, but there is a lack of comprehensive methods to facilitate coordination between the hardware and software resilience mechanisms. Often solutions are designed and deployed without fully understanding the protection coverage scope, handling capabilities and efficiency for the different fault models. There are also no established mechanisms and interfaces to connect techniques across layers of the system stack, nor are existing resilience solutions portable to newer HPC system architectures.

The design patterns are intended to enable structured design and refinement of resilience solutions by using the patterns as building blocks. We believe that the patterns support the design of solutions with a clear understanding of their protection coverage and performance efficiency. Patterns also help in constructing cross-layered resilience solutions that combine capabilities from different layers of the system stack, which effectively balance the performance, resilience, and power consumption. Such systematically designed and well-engineered resilience solutions will be the key to effective and resource-efficient use of the next-generation extreme-scale systems

The basic, abstract template of a resilience design pattern is defined in an event-driven paradigm, in which each resilience design pattern consists of a behavior and a set of activation and response interfaces. Each pattern describes a problem which occurs on account of a fault, error or failure event, and then describes the core of the solution to that problem. The patterns are written in a prescribed format that describes the problem, solution, design considerations and forces, and the consequences of applying the pattern to various contexts. In this remainder of this section, we summarize the various 
resilience design patterns. The complete pattern catalog, which contains detailed descriptions of the patterns, is available as a specification document [Hukerikar and Engelmann 2016].

\subsection{Strategy Patterns}

The strategy patterns define high-level polices of a resilience solution. Their descriptions are deliberately abstract to enable hardware and software architects to reason about the overall organization of the techniques used and their implications on the full system design. These patterns describe the overall structure of the solution and the key attributes of the solution and their capabilities independent of the layer of system stack and hardware/software architectural features.

\begin{tabular}{|c|c|c|c|c|}
\hline \multicolumn{5}{|c|}{ Strategy Patterns } \\
\hline Pattern Name & Problem & Solution & Forces & Consequences \\
\hline $\begin{array}{l}\text { FAULT } \\
\text { TREATMENT }\end{array}$ & $\begin{array}{l}\text { The presence of defects } \\
\text { or anomalies in a system } \\
\text { have the potential to acti- } \\
\text { vate, which may potentially } \\
\text { lead to an error or a par- } \\
\text { tial/complete failure of the } \\
\text { system. }\end{array}$ & $\begin{array}{l}\text { The pattern attempts to rec- } \\
\text { ognize the defect and cre- } \\
\text { ates conditions that pre- } \\
\text { vents its activation. The so- } \\
\text { lution requires a monitor- } \\
\text { ing system that observes the } \\
\text { key parameters of the moni- } \\
\text { tored system. }\end{array}$ & $\begin{array}{l}\text { The interactions of the mon- } \\
\text { itoring and monitored sys- } \\
\text { tems may interfere with } \\
\text { the operation of the system; } \\
\text { During the interval for the } \\
\text { monitoring system to infer } \\
\text { the presence of a fault, it } \\
\text { may activate. }\end{array}$ & $\begin{array}{l}\text { By preemptively recogniz- } \\
\text { ing faults in the system, the } \\
\text { pattern prevents their ac- } \\
\text { tivation, which avoids the } \\
\text { need for expensive recov- } \\
\text { ery and/or compensation ac- } \\
\text { tions. Requires an addi- } \\
\text { tional monitoring system } \\
\text { that interferes with system } \\
\text { operation. }\end{array}$ \\
\hline RECOVERY & $\begin{array}{l}\text { The occurrence of errors or } \\
\text { partial/complete failures in } \\
\text { an HPC environment pre- } \\
\text { vents applications from run- } \\
\text { ning correctly. }\end{array}$ & $\begin{array}{l}\text { The pattern attempts to } \\
\text { recreate the state of the } \\
\text { system before the occur- } \\
\text { rence of an error or failure } \\
\text { event. The pattern requires } \\
\text { that the system is capable } \\
\text { of compartmentalizing and } \\
\text { preserving its state for later } \\
\text { recovery. }\end{array}$ & $\begin{array}{l}\text { During error or failure-free } \\
\text { operation of the system, the } \\
\text { pattern incurs overhead for } \\
\text { preserving the system state. }\end{array}$ & $\begin{array}{l}\text { The pattern handles an er- } \\
\text { ror or a failure by substitut- } \\
\text { ing an error-free state from } \\
\text { the stable storage in place } \\
\text { of the erroneous state. Re- } \\
\text { quires periodic creation of } \\
\text { recoverable state, which in- } \\
\text { curs overhead proportional } \\
\text { to size of state captured and } \\
\text { frequency of state snapshot } \\
\text { creation. }\end{array}$ \\
\hline COMPENSATION & $\begin{array}{l}\text { Errors or partial/complete } \\
\text { failures in an HPC environ- } \\
\text { ment cause applications to } \\
\text { experience errors or fail. }\end{array}$ & $\begin{array}{l}\text { The pattern accounts for the } \\
\text { error or failure by maintain- } \\
\text { ing sufficient redundancy in } \\
\text { the system design. The pat- } \\
\text { tern is based on the defi- } \\
\text { nition of modules in a sys- } \\
\text { tem (with well-defined in- } \\
\text { puts and outputs), about } \\
\text { which redundant informa- } \\
\text { tion is maintained. }\end{array}$ & $\begin{array}{l}\text { The pattern introduces a } \\
\text { penalty in terms of time (in- } \\
\text { crease in execution time), } \\
\text { or space (increase in re- } \\
\text { sources required) indepen- } \\
\text { dent of whether an error or } \\
\text { failure occurs during system } \\
\text { operation. }\end{array}$ & $\begin{array}{l}\text { An error or failure in one } \\
\text { of the modules is tolerated } \\
\text { by substituting the mod- } \\
\text { ule with another replica } \\
\text { module. The replica must } \\
\text { be functionally identical to } \\
\text { module it replaces, which in- } \\
\text { curs cost and/or operation } \\
\text { overhead. }\end{array}$ \\
\hline
\end{tabular}

Table I. : Strategy Patterns

\subsection{Architectural Patterns}

The architectural patterns convey specific methods necessary for the construction of a resilience solution. They explicitly convey the type of fault, error, or failure event that they handle and provide detail about the key components and connectors that make up the solution. 
Architectural Patterns

\begin{tabular}{|c|c|c|c|c|}
\hline \multicolumn{5}{|c|}{ Architectural Patterns } \\
\hline Pattern Name & Problem & Solution & Forces & Consequences \\
\hline FAULT DIAGNOSIS & $\begin{array}{l}\text { An incomplete understand- } \\
\text { ing of the cause and impact } \\
\text { of a fault in an HPC system } \\
\text { design makes design pro- } \\
\text { cess of remedial actions dif- } \\
\text { ficult. }\end{array}$ & $\begin{array}{l}\text { The pattern is a deriva- } \\
\text { tive of the FAULT TREAT- } \\
\text { MENT pattern and its solu- } \\
\text { tion is based on the capabil- } \\
\text { ity of a monitoring system } \\
\text { to analyze the behavior of } \\
\text { the monitored system. }\end{array}$ & $\begin{array}{l}\text { During the time interval for } \\
\text { the monitoring system to di- } \\
\text { agnose the fault, it may ac- } \\
\text { tivate to cause an error or } \\
\text { failure; The degree of accu- } \\
\text { racy of the fault diagnosis } \\
\text { must be high }\end{array}$ & $\begin{array}{l}\text { The pattern only infers the } \\
\text { presence of a defect and re- } \\
\text { ports it, but does act to rem- } \\
\text { edy the fault. }\end{array}$ \\
\hline RECONFIGURATION & $\begin{array}{l}\text { The presence of a fault, er- } \\
\text { ror or failure event may } \\
\text { affect configuration of the } \\
\text { system components, pre- } \\
\text { venting its correct opera- } \\
\text { tion. }\end{array}$ & $\begin{array}{l}\text { The pattern is a deriva- } \\
\text { tive of the FAULT TREAT- } \\
\text { MENT and the RECOV- } \\
\text { ERY strategy pattern and } \\
\text { its solution entails modifi- } \\
\text { cation of the interconnec- } \\
\text { tion between modules in } \\
\text { the system as means to pre- } \\
\text { vent activation of a fault, or } \\
\text { to recover the system from } \\
\text { an error or a failure event. }\end{array}$ & $\begin{array}{l}\text { The system design must al- } \\
\text { low for encapsulation of sys- } \\
\text { tem functions into a set of } \\
\text { well-defined modules such } \\
\text { that a subset of modules } \\
\text { is functionally equivalent to } \\
\text { the fault, error, or failure- } \\
\text { free version of the system. }\end{array}$ & $\begin{array}{l}\text { The pattern is based on } \\
\text { the encapsulation of system } \\
\text { functions into a set of well- } \\
\text { defined modules. }\end{array}$ \\
\hline $\begin{array}{l}\text { CHECKPOINT- } \\
\text { RECOVERY }\end{array}$ & $\begin{array}{l}\text { An unrecoverable error or } \\
\text { a failure events in an HPC } \\
\text { environment prevents the } \\
\text { execution of applications. }\end{array}$ & $\begin{array}{l}\text { The pattern is derivative of } \\
\text { the RECOVERY pattern, } \\
\text { whose solution entails } \\
\text { maintenance of partial } \\
\text { or complete system state } \\
\text { on stable storage during } \\
\text { error/failure-free opera- } \\
\text { tion, or using log-based } \\
\text { protocols, which creates } \\
\text { a log of non-deterministic } \\
\text { events in the system. }\end{array}$ & $\begin{array}{l}\text { The pattern requires stable } \\
\text { storage to capture sys- } \\
\text { tem state or to log events, } \\
\text { which increase overhead } \\
\text { in terms of resources re- } \\
\text { quired by the system; Incurs } \\
\text { error/failure-free overhead } \\
\text { to performance }\end{array}$ & $\begin{array}{l}\text { Upon detection of an error } \\
\text { or a failure, the check- } \\
\text { points/log events are used } \\
\text { to recreate last known } \\
\text { error/failure-free state of } \\
\text { the system before restart- } \\
\text { ing the system. Requires } \\
\text { periodic creation of recov- } \\
\text { erable state, which incurs } \\
\text { overhead proportional to } \\
\text { size of state captured and } \\
\text { frequency of state snapshot } \\
\text { creation. }\end{array}$ \\
\hline REDUNDANCY & $\begin{array}{l}\text { The occurrence of error or } \\
\text { failure events caused by } \\
\text { physical faults in an HPC } \\
\text { environment prevents the } \\
\text { execution of applications. }\end{array}$ & $\begin{array}{l}\text { Pattern is a derivative of } \\
\text { the COMPENSATION pat- } \\
\text { tern; the solution entails } \\
\text { creation of multiple redun- } \\
\text { dant versions of a system. } \\
\text { The pattern enables a sys- } \\
\text { tem to tolerate faults that } \\
\text { occur because of random } \\
\text { phenomena based on the } \\
\text { assumption that the ran- } \\
\text { dom event is unlikely to af- } \\
\text { fect the replicas. }\end{array}$ & $\begin{array}{l}\text { The pattern introduces } \\
\text { penalty in terms of time (in- } \\
\text { crease in execution time), or } \\
\text { space (increase in resources } \\
\text { required) independent of } \\
\text { whether an errors or failure } \\
\text { occurs }\end{array}$ & $\begin{array}{l}\text { The pattern results in a } \\
\text { system design consisting of } \\
\text { group of N identical repli- } \\
\text { cas of a system's hardware } \\
\text { or software components, but } \\
\text { there is an implicit assump- } \\
\text { tion of independence of oper- } \\
\text { ation between replicas of the } \\
\text { system. }\end{array}$ \\
\hline $\begin{array}{l}\text { DESIGN } \\
\text { DIVERSITY }\end{array}$ & $\begin{array}{l}\text { Design faults introduced by } \\
\text { human mistakes or defec- } \\
\text { tive design tools cause sys- } \\
\text { tems to malfunction or fail }\end{array}$ & $\begin{array}{l}\text { The pattern is also a } \\
\text { derivative of the COM- } \\
\text { PENSATION pattern, but } \\
\text { is based on an approach } \\
\text { in which the hardware } \\
\text { and software elements } \\
\text { for multiple computations } \\
\text { are not identical copies, } \\
\text { but are independently de- } \\
\text { signed to meet the system's } \\
\text { requirements. }\end{array}$ & $\begin{array}{l}\text { Distinct implementations of } \\
\text { the same design specifi- } \\
\text { cation, which are created } \\
\text { by different individuals or } \\
\text { teams, incur designer effort } \\
\text { and verification costs }\end{array}$ & $\begin{array}{l}\text { The pattern requires dis- } \\
\text { tinct implementations of the } \\
\text { same design specification, } \\
\text { which are created by dif- } \\
\text { ferent individuals or teams, } \\
\text { and with different design } \\
\text { tools to systematically avoid } \\
\text { design bugs. }\end{array}$ \\
\hline
\end{tabular}

Table II. : Architectural Patterns 


\subsection{Structural Patterns}

The structural patterns provide concrete descriptions of the solution rather than high-level strategies. They comprise of instructions that may be implemented in hardware/software components. While the strategy and architectural patterns serve to provide designers with a clear overall framework of a solution and the type of events that it can handle, the structural patterns express the details so they can contribute to the development of complete working solutions.

\begin{tabular}{|c|c|c|c|c|}
\hline \multicolumn{5}{|c|}{ Structural Patterns } \\
\hline Pattern Name & Problem & Solution & Forces & Consequences \\
\hline MONITORING & $\begin{array}{l}\text { The presence of a defect or } \\
\text { anomaly in the system may } \\
\text { result in an error or failure }\end{array}$ & $\begin{array}{l}\text { Derivative pattern of the } \\
\text { fault diagnosis architec- } \\
\text { tural pattern. The solution } \\
\text { identifies faults based on } \\
\text { one of two strategies: the } \\
\text { effect-cause diagnosis, or } \\
\text { the cause-effect diagnosis. }\end{array}$ & $\begin{array}{l}\text { The interactions between } \\
\text { the monitoring and moni- } \\
\text { tored systems may interfere } \\
\text { with the operation of the } \\
\text { system }\end{array}$ & $\begin{array}{l}\text { The monitoring pattern } \\
\text { causes overhead to system } \\
\text { operation on account of } \\
\text { the additional hardware } \\
\text { or software components } \\
\text { required for observation of } \\
\text { the system and the cause } \\
\text { and effect analysis. }\end{array}$ \\
\hline PREDICTION & $\begin{array}{l}\text { Recognizing system condi- } \\
\text { tions that may cause faults } \\
\text { may help prevent an error } \\
\text { or failure event in the sys- } \\
\text { tem. }\end{array}$ & $\begin{array}{l}\text { The solution enables antic- } \\
\text { ipation of fault events us- } \\
\text { ing the rule-based method } \\
\text { (building rules of associa- } \\
\text { tion to capture the causal } \\
\text { correlations between sys- } \\
\text { tem parameter values and } \\
\text { fault events), or statistical } \\
\text { methods (using probabilis- } \\
\text { tic characteristics) to pre- } \\
\text { dict the occurrence of future } \\
\text { fault events. }\end{array}$ & $\begin{array}{l}\text { The time interval for pre- } \\
\text { diction must be minimized; } \\
\text { degree of accuracy must be } \\
\text { high to prevent false posi- } \\
\text { tives. }\end{array}$ & $\begin{array}{l}\text { The prediction adds over- } \\
\text { head to system operation, } \\
\text { which is related to the com- } \\
\text { plexity of the prediction al- } \\
\text { gorithm. The pattern also } \\
\text { incurs overheads on account } \\
\text { of actions taken based on in- } \\
\text { correct predictions, i.e., false } \\
\text { positives and false nega- } \\
\text { tives. }\end{array}$ \\
\hline RESTRUCTURE & $\begin{array}{l}\text { The occurrence of a fault, or } \\
\text { a resulting error or failure } \\
\text { affects the configuration of } \\
\text { a system such that correct } \\
\text { system operation is not pos- } \\
\text { sible }\end{array}$ & $\begin{array}{l}\text { The solution is based on } \\
\text { modifying the configuration } \\
\text { between the } \mathrm{N} \text { intercon- } \\
\text { nected subsystems to iso- } \\
\text { late the subsystem affected } \\
\text { by a fault, error or fail- } \\
\text { ure. The pattern is a deriva- } \\
\text { tive of the RECONFIGURA- } \\
\text { TION architectural pattern. }\end{array}$ & $\begin{array}{l}\text { The restructuring may } \\
\text { cause the system to operate } \\
\text { in degraded state using } \\
\text { fewer than } \mathrm{N} \text { sub-systems. }\end{array}$ & $\begin{array}{l}\text { This pattern seeks to ex- } \\
\text { clude only the affected } \\
\text { subsystem from interaction } \\
\text { with other subsystems. The } \\
\text { resulting system configura- } \\
\text { tion must be functionally } \\
\text { equivalent to the system } \\
\text { before the occurrence of the } \\
\text { event, which is often hard } \\
\text { to guarantee. }\end{array}$ \\
\hline REJUVENATION & $\begin{array}{l}\text { A fault event, or a result- } \\
\text { ing error or failure causes a } \\
\text { sub-system to operate incor- } \\
\text { rectly, which prevents cor- } \\
\text { rect system operation. }\end{array}$ & $\begin{array}{l}\text { The pattern isolates the spe- } \\
\text { cific part of the system af- } \\
\text { fected by an event and only } \\
\text { restores or recreates the af- } \\
\text { fected state with the goal of } \\
\text { enabling the system to re- } \\
\text { sume normal operation. The } \\
\text { pattern is also a deriva- } \\
\text { tive of the RECONFIGURA- } \\
\text { TION pattern. }\end{array}$ & $\begin{array}{l}\text { The solution requires sub- } \\
\text { stantial additional overhead } \\
\text { to identify the part of the } \\
\text { system affected and perform } \\
\text { selective reinitialization. }\end{array}$ & $\begin{array}{l}\text { The solution requires pre- } \\
\text { cise identification of the sub- } \\
\text { system affected by a fault, } \\
\text { error or failure, and re- } \\
\text { setting its configuration to } \\
\text { guarantee recovery of the } \\
\text { overall system. }\end{array}$ \\
\hline REINITIALIZATION & $\begin{array}{l}\text { A fault, error or failure } \\
\text { event affects a system to the } \\
\text { extent that restoring correct } \\
\text { operation is impossible. }\end{array}$ & $\begin{array}{l}\text { The pattern performs a re- } \\
\text { set of the system state to } \\
\text { restore pristine state be- } \\
\text { fore system operation is re- } \\
\text { sumed. The pattern is also } \\
\text { a derivative of the RECON- } \\
\text { FIGURATION pattern. }\end{array}$ & $\begin{array}{l}\text { The reinitialization causes } \\
\text { loss of all forward progress } \\
\text { made by system, but is es- } \\
\text { sential when the effects of } \\
\text { an error or failure are unre- } \\
\text { coverable. }\end{array}$ & $\begin{array}{l}\text { The reinitialization is of- } \\
\text { ten a slow process, but of- } \\
\text { fers the opportunity to com- } \\
\text { pletely remove any effects of } \\
\text { the fault, error, or failure. }\end{array}$ \\
\hline
\end{tabular}




\begin{tabular}{|c|c|c|c|c|}
\hline ROLLBACK & $\begin{array}{l}\text { The occurrence of an error } \\
\text { or failure event prevents for- } \\
\text { ward progress of a system. }\end{array}$ & $\begin{array}{l}\text { The pattern periodically } \\
\text { captures system state } \\
\text { during regular opera- } \\
\text { tion. The pattern may } \\
\text { also use log-based proto- } \\
\text { cols for non-deterministic } \\
\text { events in the system. The } \\
\text { pattern is a derivative } \\
\text { of the CHECKPOINT- } \\
\text { RECOVERY architectural } \\
\text { pattern. Therefore, recovery } \\
\text { is performed by restoring } \\
\text { the system to the last } \\
\text { known stable state. }\end{array}$ & $\begin{array}{l}\text { Frequent checkpointing in- } \\
\text { creases system execution } \\
\text { time, but reduces amount of } \\
\text { lost work upon occurrence of } \\
\text { an error or failure. }\end{array}$ & $\begin{array}{l}\text { The pattern introduces } \\
\text { overhead during failure-free } \\
\text { operation proportional to } \\
\text { the size of the system state } \\
\text { captured and frequency } \\
\text { of checkpointing. How- } \\
\text { ever, amount of lost work } \\
\text { when failure does occur } \\
\text { is inversely related to the } \\
\text { frequency of checkpointing. }\end{array}$ \\
\hline ROLLFORWARD & $\begin{array}{l}\text { The impact of an error or } \\
\text { failure prevents correct op- } \\
\text { eration of a system. }\end{array}$ & $\begin{array}{l}\text { Similar to the ROLLBACK } \\
\text { pattern, the solution is } \\
\text { based on committing sys- } \\
\text { tem state to persistent } \\
\text { storage, or use logging of } \\
\text { non-deterministic system } \\
\text { events. The defining feature } \\
\text { of the pattern is the forward } \\
\text { recovery, which restarts } \\
\text { operation from the point the } \\
\text { system had reached right } \\
\text { before the occurrence of the } \\
\text { error/failure. }\end{array}$ & $\begin{array}{l}\text { The post-recovery state of } \\
\text { the system created during } \\
\text { roll-forward must require } \\
\text { minimum recomputation. }\end{array}$ & $\begin{array}{l}\text { The rollforward operation is } \\
\text { often less expensive than } \\
\text { rollback algorithm. }\end{array}$ \\
\hline $\begin{array}{l}\text { FORWARD } \\
\text { ERROR } \\
\text { CORRECTION } \\
\text { CODE }\end{array}$ & $\begin{array}{l}\text { The presence of information } \\
\text { errors in a system's state af- } \\
\text { fects its correct operation. }\end{array}$ & $\begin{array}{l}\text { The solution offered by the } \\
\text { pattern consists of encoding } \\
\mathrm{k} \text { information symbols that } \\
\text { represent the system state } \\
\text { and appending a set of } \mathrm{r} \\
\text { additional symbols. The in- } \\
\text { tegrity of the original in- } \\
\text { formation and the recovery } \\
\text { of any corrupted symbols is } \\
\text { performed by decoding the } \\
\text { encoded state. The pattern } \\
\text { is derived from the REDUN- } \\
\text { DANCY pattern. }\end{array}$ & $\begin{array}{l}\text { The strength of the cor- } \\
\text { rection code in terms of } \\
\text { number of symbols incurs } \\
\text { encoding/decoding time } \\
\text { and space overhead, but } \\
\text { stronger codes provide } \\
\text { protection against multi- } \\
\text { symbol state errors. }\end{array}$ & $\begin{array}{l}\text { The encoding and decod- } \\
\text { ing process incurs overhead } \\
\text { each time an information } \\
\text { symbol is accessed and/or } \\
\text { manipulated. The amount of } \\
\text { recoverable information de- } \\
\text { pends on the number of ad- } \\
\text { ditional encoding bits are } \\
\text { maintained. }\end{array}$ \\
\hline $\begin{array}{l}\text { N-MODULAR } \\
\text { REDUNDANCY }\end{array}$ & $\begin{array}{l}\text { The pattern solves the prob- } \\
\text { lem of dealing with errors, } \\
\text { as well as partial or com- } \\
\text { plete failures. }\end{array}$ & $\begin{array}{l}\text { The pattern entails cre- } \\
\text { ation of a group of } \mathrm{N} \text { iden- } \\
\text { tical replicas of the sys- } \\
\text { tem. Each of the } \mathrm{N} \text { repli- } \\
\text { cas may be active simulta- } \\
\text { neously in various config- } \\
\text { urations: spatial, temporal, } \\
\text { or active on-demand repli- } \\
\text { cation. This pattern is also } \\
\text { a derivative of the REDUN- } \\
\text { DANCY architectural pat- } \\
\text { tern }\end{array}$ & $\begin{array}{l}\text { The n-factor replication of } \\
\text { system operation introduces } \\
\text { cost and overhead; scope of } \\
\text { replication and its inputs, } \\
\text { outputs must be carefully } \\
\text { selected. }\end{array}$ & $\begin{array}{l}\text { In order to recover from } 2 \mathrm{~N} \\
\text { errors/failures in the sys- } \\
\text { tem, there must be } 2 \mathrm{~N}+1 \\
\text { distinct replicas of the sys- } \\
\text { tem. Since the replicas are } \\
\text { identical the design effort is } \\
\text { low, but overhead of creating } \\
\mathrm{N} \text { replicas incurs overhead } \\
\text { in terms of resources and/or } \\
\text { operation time. }\end{array}$ \\
\hline $\begin{array}{l}\text { N-VERSION } \\
\text { DESIGN }\end{array}$ & $\begin{array}{l}\text { Design bugs may manifest } \\
\text { themselves during system } \\
\text { operation causing incorrect } \\
\text { operation or failure. }\end{array}$ & $\begin{array}{l}\text { The pattern entails creation } \\
\text { of distinct implementations } \\
\text { of the same design speci- } \\
\text { fication, which are created } \\
\text { by different individuals or } \\
\text { teams and with separate de- } \\
\text { sign tools. The pattern is a } \\
\text { derivative of the DESIGN } \\
\text { DIVERSITY pattern. }\end{array}$ & $\begin{array}{l}\text { The distinct implementa- } \\
\text { tion versions of the same de- } \\
\text { sign specification must be } \\
\text { created by different teams } \\
\text { or individuals, and must be } \\
\text { verified independently. }\end{array}$ & $\begin{array}{l}\text { The versions of the sys- } \\
\text { tem are functionally identi- } \\
\text { cal, but designed indepen- } \\
\text { dently which requires sig- } \\
\text { nificant amount of design } \\
\text { and implementation effort, } \\
\text { particularly for complex sys- } \\
\text { tem specifications. }\end{array}$ \\
\hline
\end{tabular}




\begin{tabular}{|c|c|c|c|c|}
\hline $\begin{array}{l}\text { RECOVERY } \\
\text { BLOCK }\end{array}$ & $\begin{array}{l}\text { Flaws in the design on } \\
\text { account of human errors } \\
\text { and/or faulty tools may } \\
\text { cause errors or failures } \\
\text { during system operation }\end{array}$ & $\begin{array}{l}\text { The solution is based on } \\
\text { partitioning the system into } \\
\text { distinct functional blocks, in } \\
\text { which each block contains } \\
\text { at least a primary design } \\
\text { and exceptional case han- } \\
\text { dler along with an adjudica- } \\
\text { tor subsystem. This pattern } \\
\text { is also a derivative of the } \\
\text { DESIGN DIVERSITY pat- } \\
\text { tern. }\end{array}$ & $\begin{array}{l}\text { The recovery block must } \\
\text { be comprehensive in de- } \\
\text { tecting and recovering er- } \\
\text { rors caused by design flaws, } \\
\text { without requiring the de- } \\
\text { sign complexity or verifica- } \\
\text { tion effort of a full system } \\
\text { design. }\end{array}$ & $\begin{array}{l}\text { The pattern requires devel- } \\
\text { opment of a comprehensive } \\
\text { acceptance test to validate } \\
\text { the result produced by the } \\
\text { primary system for various } \\
\text { types of design bugs. }\end{array}$ \\
\hline
\end{tabular}

Table III. : Structural Patterns

\subsection{State Patterns}

The state patterns describe all aspects of the system structure that are relevant to the forward progress of the system. The correctness and consistency of the system state ensures that the correct operation of the system. These patterns implicitly define the scope of the protection domain that must be covered by a resilience mechanism. The state patterns expose an intrinsic property of the system.

\begin{tabular}{|c|c|c|c|c|}
\hline \multicolumn{5}{|c|}{ State Patterns } \\
\hline Pattern Name & Problem & Solution & Forces & Consequences \\
\hline $\begin{array}{l}\text { PERSISTENT } \\
\text { STATE }\end{array}$ & $\begin{array}{l}\text { The scope of the system } \\
\text { state that remains un- } \\
\text { changed for the entire } \\
\text { duration of system opera- } \\
\text { tion has unique resilience } \\
\text { needs from other aspects of } \\
\text { the state. }\end{array}$ & $\begin{array}{l}\text { Encapsulates all aspects of } \\
\text { a systems state that is com- } \\
\text { puted when the system is } \\
\text { initialized, but is not modi- } \\
\text { fied during the system oper- } \\
\text { ation. }\end{array}$ & $\begin{array}{l}\text { The precise definition of } \\
\text { persistent system state } \\
\text { requires a detailed un- } \\
\text { derstanding of the system } \\
\text { structure and operation. }\end{array}$ & $\begin{array}{l}\text { The encapsulation of such } \\
\text { state enables selection of be- } \\
\text { havior patterns that lever- } \\
\text { age the persistent property } \\
\text { for detection and mitigation } \\
\text { of faults and errors. }\end{array}$ \\
\hline DYNAMIC STATE & $\begin{array}{l}\text { The scope of the system } \\
\text { state that changes as a re- } \\
\text { sult of the system operation } \\
\text { has unique resilience needs } \\
\text { from other aspects of the } \\
\text { state. }\end{array}$ & $\begin{array}{l}\text { Defines the scope of the } \\
\text { system state that changes } \\
\text { during system operation as } \\
\text { the system makes forward } \\
\text { progress. }\end{array}$ & $\begin{array}{l}\text { Precisely scoping the state } \\
\text { that changes during opera- } \\
\text { tion requires complex anal- } \\
\text { ysis. }\end{array}$ & $\begin{array}{l}\text { The definition of scope of the } \\
\text { system state related to sys- } \\
\text { tem's operation enables the } \\
\text { selection of patterns that } \\
\text { ensure consistency of the } \\
\text { state when performing mit- } \\
\text { igation actions. }\end{array}$ \\
\hline $\begin{array}{l}\text { ENVIRONMENT } \\
\text { STATE }\end{array}$ & $\begin{array}{l}\text { The scope of the system } \\
\text { state that provide a common } \\
\text { set of services that support } \\
\text { of primary system function } \\
\text { has unique resilience needs } \\
\text { from other aspects of the } \\
\text { state. }\end{array}$ & $\begin{array}{l}\text { Defines the scope of the sys- } \\
\text { tem state that provides ser- } \\
\text { vices to the system. }\end{array}$ & $\begin{array}{l}\text { Separation of the system } \\
\text { state that provides a com- } \\
\text { mon set of services requires } \\
\text { modular design and well- } \\
\text { defined abstractions }\end{array}$ & $\begin{array}{l}\text { The encapsulation of the en- } \\
\text { vironment state enables de- } \\
\text { signers to instantiate be- } \\
\text { havioral patterns that pro- } \\
\text { vide detection and mitiga- } \\
\text { tion of faults and errors } \\
\text { within the supporting ser- } \\
\text { vices. }\end{array}$ \\
\hline STATELESS & $\begin{array}{l}\text { Several resilience strategies } \\
\text { operate with the need for a } \\
\text { specified protection domain. }\end{array}$ & $\begin{array}{l}\text { Provides the construct of } \\
\text { null state in order to create } \\
\text { solutions that have a well- } \\
\text { defined notion of behavior } \\
\text { but need not define a scope } \\
\text { for a protection domain. }\end{array}$ & $\begin{array}{l}\text { With a stateless pattern, } \\
\text { understanding the scope } \\
\text { and impact of a resilience } \\
\text { solution on a system is } \\
\text { difficult. }\end{array}$ & $\begin{array}{l}\text { By defining the scope of } \\
\text { stateless pattern enables in- } \\
\text { stantiation of behavior pat- } \\
\text { terns that do not need to } \\
\text { worry about side-effects of } \\
\text { their mitigation actions on } \\
\text { system state. }\end{array}$ \\
\hline
\end{tabular}

Table IV. : State Patterns 


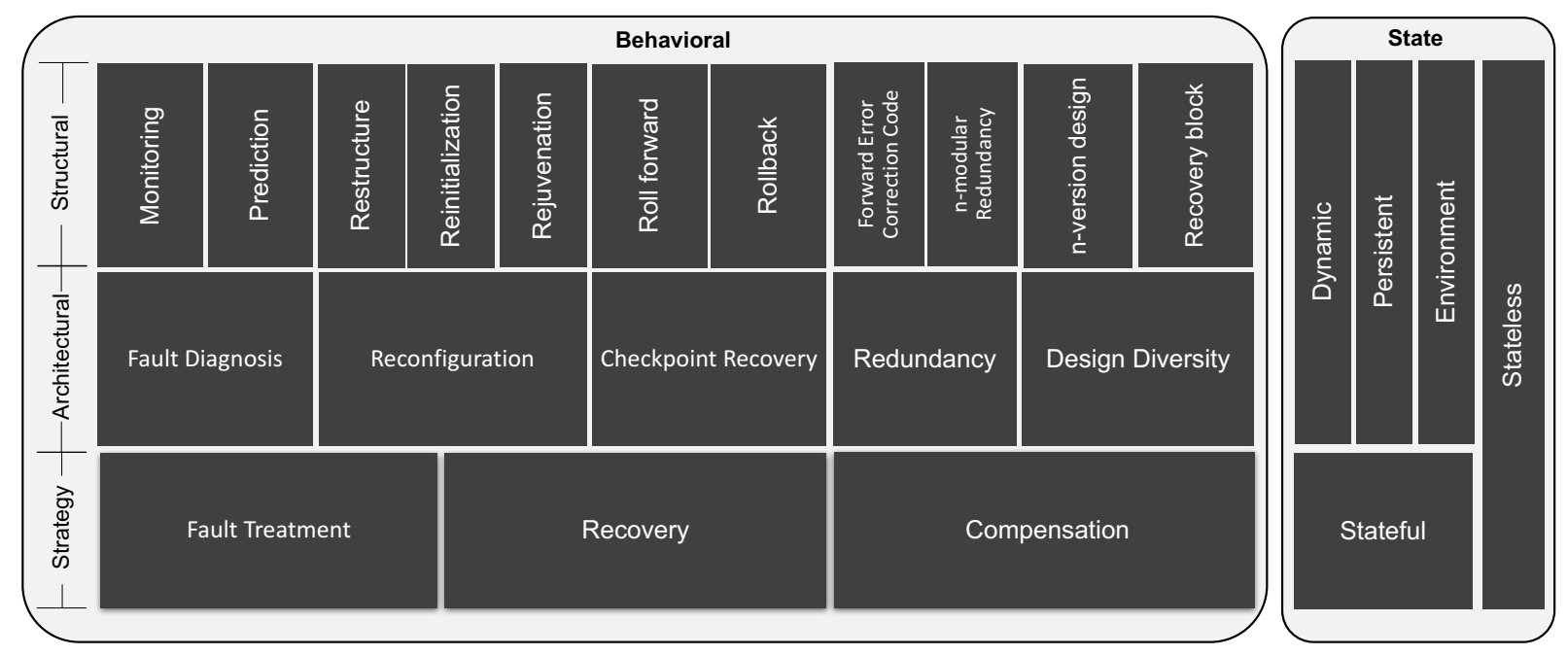

Fig. 1: Classification of Resilience Design Patterns

\section{CLASSIFICATION OF RESILIENCE DESIGN PATTERNS}

Due to the variety in the granularity and level of system abstraction at which each of the patterns may be implemented, we developed an ad-hoc classification scheme to organize the patterns in our resilience design pattern specification [Hukerikar and Engelmann 2016]. In this scheme, which is illustrated in Figure 1, the patterns are organized in a layered hierarchy.

HPC resilience solutions emphasize the reliability and performance efficiency of an application's execution with the acceptance that the underlying hardware and software environment experiences numerous faults, degradations and component failures [DeBardeleben et al. 2009]. Based on this perspective, HPC resilience has two important aspects, namely the forward progress of an application and the consistency and fidelity of an application's data. Accordingly, we have organized the patterns in the catalog into two broad categories: state patterns and behavioral patterns.

The state patterns (described in Section 3) define the protection domain of a resilience solution. These patterns encapsulate particular aspects of a program's state. The different types of state patterns, namely static, dynamic and environment make it possible to define the resilience behavior in a modular fashion; the specific domain scoped by each state pattern may be associated with different resilience techniques. The selection of the state pattern also helps define the containment scope, i.e., the scope of how far a fault or error event propagates.

The behavioral patterns (described in Section 3) identify detection, containment, mitigation techniques that enable a system, which instantiates and implements these patterns, to cope with the presence of fault, error, or failure events. These patterns are organized in a layered hierarchy that describes the patterns from abstract to concrete descriptions of the techniques. The strategy patterns in the bottom layer are organized by the type of event that they are intended to handle, i.e., whether it is a fault, error or failure. The architectural patterns are organized by the specific fault, error or failure types and describe key components and connectors of the pattern solution. The structural patterns in the top layer provide concrete descriptions of the solutions. Their descriptions often contain specific instructions that may be implemented in hardware or software components. 
This classification scheme enables designers to separately reason about scope of the protection domain and the semantics of a resilience pattern's behavior. This hierarchical organization of the behavioral patterns reveals the relationships among these resilience patterns. This classification scheme suggests a number of ways in which these patterns can be combined. Designers may approach the task of developing a complete resilience solution by navigating the hierarchy in top-down or bottom-up manner. This provides the designers with guidelines for selecting patterns for a specific context and combining patterns for the realization of complete resilience solutions. Yet, this scheme leaves much to the skills of the designer since it does not completely cover the various alternative solutions that may exist to address design problems for a particular context. A more comprehensive approach to designing and implementing resilience solutions requires the definition of a pattern language.

\section{PATTERN LANGUAGE FOR HPC RESILIENCE}

A pattern language is considered as a system of patterns that are related with each other in a hierarchy or network. The structure of the network helps designers makes sense of the individual patterns, as well as helps anchor them in various combinations to provide complete solutions. Our pattern language for HPC resilience explains the discipline to use the various design patterns to create effective and efficient resilience solutions. The elements of the language are the patterns detailed in Section 3 . The language guides a designer from the beginning of a design problem to the realization of its solution.

\subsection{Types of Pattern Relations}

In general, a pattern language has the structure of a network such that patterns that are related by some measure of relevance are linked together. The definition of the linkage between patterns is the key for a set of patterns to become a language rather than be seen as a collection of isolated, standalone ideas for design.

In contrast to a pattern classification, which provides the means to group patterns based on a set of rules or pattern properties, a pattern language explicitly interweaves the patterns in the catalog based on every possible (but at least one) type of pattern interrelation. Based on the interrelations between the patterns, the complete set of the resilience patterns in the catalog forms a language. Therefore, making these relations explicit is essential to the process of developing a pattern language.

Table V. : Types of Pattern Relations

\begin{tabular}{|c|c|c|}
\hline Pattern Relation & Description & Inverse Relation \\
\hline abstraction & Pattern $\mathrm{x}$ describes an abstract form of pattern $\mathrm{y}$ & specialization \\
\hline specialization & Pattern $\mathrm{x}$ provides specific details about pattern $\mathrm{y}$ & abstraction \\
\hline used with & $\begin{array}{l}\text { Pattern } \mathrm{x} \text { is used to address different problem than y; may be } \\
\text { used together }\end{array}$ & conflict \\
\hline conflict & $\begin{array}{l}\text { Pattern } \mathrm{x} \text { and } \mathrm{y} \text { are not suitable to be applied together for a } \\
\text { specific problem }\end{array}$ & used with \\
\hline similarity & $\begin{array}{l}\text { Pattern } \mathrm{x} \text { and y have some similar features, but address dif- } \\
\text { ferent problems }\end{array}$ & - \\
\hline domain & $\begin{array}{l}\text { Pattern } \mathrm{x} \text { specifies the protection domain for the behavioral } \\
\text { pattern } \mathrm{y}\end{array}$ & - \\
\hline
\end{tabular}


Highlighting these relationships between patterns enables designers to grasp the entire collection of patterns. Therefore, the pattern language also serves as an index to the catalog of resilience design patterns. For the resilience design patterns, various types of pattern relations may be used to express kinds of relatedness between the patterns. Table $\mathrm{V}$ provides an overview of the types of relationships between the resilience patterns. These interrelations between the patterns form the links between patterns in the network, thereby defining the order in which the patterns should be applied to a HPC resilience design.

\subsection{Structure of the Pattern Language}

Forming a pattern language requires establishing rules for linking each of the patterns in the catalog. This is a particularly complex task for resilience design patterns due to their large number and the various design considerations and optimizations that must be accounted for. To enable designers to understand the language and for rapid analysis of the relationships between the various resilience design patterns, we have represented the pattern language using a graph. Each pattern is represented as a vertex and every relation between any two patterns is represented by an edge in the graph network. Based on the type of relation between the patterns, the edges may be directed or undirected. This representation of our pattern language is shown in Figure 2.

The pattern graph represents the language since it captures all the interrelations between the resilience patterns. This representation of the language is intended to make these patterns useful for a broad target audience. System architects may use the language to understand the scope of the problem and develop a high-level layout of the pattern-based solution, while the designers of individual component may use the language to understand the pattern relationships that directly impacts their part of the design.

The use of the graph representation of the pattern language also enables structured analysis of resilience solutions. For example, a simulator may use the graph representation of the pattern language for design space exploration to evaluate alternative combinations of patterns that may have different complexity and performance characteristics. Similarly, the graph representation of the language may enable a runtime system or scheduler to make dynamic decisions about the suitability of instantiating a specific combination of patterns.

The graph representation of the language highlights the pattern relations (listed in Table V) between all the resilience patterns in the catalog. The vertices representing the patterns are clustered to align with the classification scheme described in Section 4 . The state patterns and the three categories of the strategy patterns are represented in different colors. The derivative patterns of each of these classes are represented in the same color as their parents. The patterns are ordered from abstract to concrete to enable designers to focus on the contours of a solution before delving into implementation specifics. Additionally, most of the relations are directed from one pattern to another, but they often also imply an inverse relation in the opposite direction. Therefore, every edge in the graph may be treated as a directed connection between patterns that highlights a specific relation between the two patterns. From the designers' perspective, this representation of the pattern language provides the methodology for selecting patterns from the catalog. The language outlines the ordering of the critical decisions that must be considered when designing and implementing a resilience solution.

\section{USING THE PATTERN LANGUAGE}

Our pattern language spans all the way from the initial architecture of a resilience solution down to the lowest level details of the implementation for a specific architecture and software environment. Defining which patterns to use and how to combine them is the very essence of the pattern language. However, an emphasis of a pattern language is often not represented in the inherent structure of the 


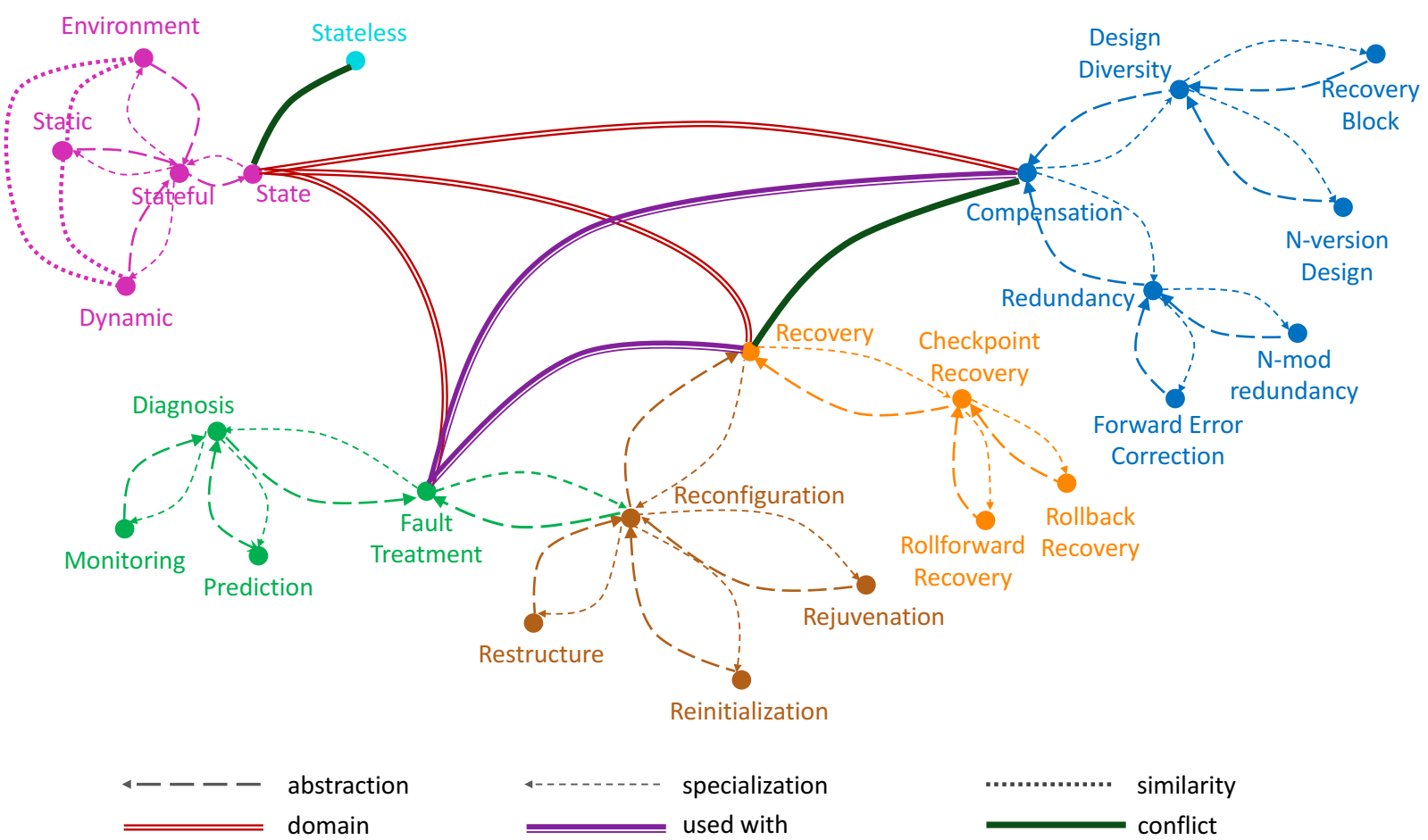

Fig. 2: Resilience Pattern Language Representation

pattern language. Since our pattern language is in the form of a network, there is no one sequence that perfectly captures the pattern relationships. Therefore, when selecting a suitable combination of patterns for constructing a resilience solution, there are numerous ways in which the network of patterns may be traversed.

\subsection{Structured Design of HPC Resilience Solutions}

The pattern language outlines the intended flow of information when reading or browsing the pattern catalog. Using the pattern language, solutions are designed incrementally by exploring the links of the network that represents the pattern language. This yields an order in which the patterns should be applied to a design problem, which is called a pattern language sequence. However, the pattern sequence is not strictly linear. Various stakeholders, including system HPC system architects, hardware and software designers, application developers and users can construct solutions by discovering a sequence that fits their design objectives and constraints. For the following key aspects of a resilience design process, the pattern language enables the discovery of pattern-based solutions:

-Protection Domain: Based on the scope of the system that the solution intends to protect, the language may traverse the network starting from the state pattern vertices, and then identify the behavioral patterns to protect the selected domain.

-Fault Model: The type of event that a solution is designed for forces the designer to consider one of the strategy pattern vertices, before exploring the network links that will enable the identification of 
derivative patterns that are capable of handling the consequences of a specific fault, error or failure type.

-Fault Management Capabilities: Based on whether the pattern offers detection, containment, recovery or masking semantics, or a combination of these capabilities, the traversal may commence at specific cluster in the graph representing the language.

-Implementation-Driven: Often the design of a resilience solution may be constrained by the idiosyncrasies of a hardware architecture or software environment, or by the availability of specific technologies for supporting a resilience solution. In this case, the pattern language may be used to identify the structural patterns first, and traverse the links of the network towards the more abstract behavioral patterns and the state patterns to evaluate the effective protection domain and capabilities.

\subsection{Other Design Considerations for Resilience Solutions}

While the pattern language for designing resilience solutions for HPC systems is intended to provide designers with a roadmap to create solutions, there are various other critical decisions that must be considered in addition to the fundamental choices of protection domain, fault model, capability and implementation mechanisms. These include:

-Design complexity of the solution: The effort necessary to incorporate the patterned solution in the overall design of a system.

- Time overhead in the absence of fault, error, or failure events: The impact of the pattern (in terms of time to solution) on the fault-free operation of a system.

-Time overhead to manage fault, error, or failure events: The impact on time to solution on account of the actions required to manage an event.

-Space overhead of the solution: The number of additional components or subsystems that the solution requires.

-Power overhead of the solution: The impact of applying the pattern on the systems power consumption.

For each optimization objective, the graph edges may be annotated with relations that express the implications of selecting a pattern when traversing the network. Using these additional relations, the pattern language may be used to discover an ordering of patterns that meets these design considerations as well as the functional requirements of a solution for confronting a specific type of fault, error or failure.

\section{RELATED WORK}

The solution space for HPC resilience constituted by a number of hardware and software-based solutions is fragmented. HPC vendors have developed a number of hardware resilience technologies, including SECDED ECC for main memory, caches, registers and architectural state, as well as, Chipkill for main memory [Dell 1997], redundant power supplies and voltage regulators, and reliability, availability and serviceability (RAS) management systems for system-level monitoring and control [Inc. 2014]. On the other hand, various software resilience technologies have been invented, including application- and system-level checkpoint/restart [Mohror et al. 2013], fault tolerance extensions to the Message Passing Interface (MPI) [Bland et al. 2013], programming models with intrinsic resilience support [Chung et al. 2012], and algorithm-based fault tolerance [Huang and Abraham 1984]. However, there hasn't been a concerted effort to develop formal methods for solution space exploration, or for coordination between multiple solutions across the system stack. The resilience design patterns 
[Hukerikar and Engelmann 2017] and the pattern language presented in this paper are intended to provide HPC designers with an approach to systematically design and implement comprehensive resilience solutions.

In the context of other types of parallel and distributed systems, the critical need for fault tolerance solutions has driven previous efforts to define design patterns for fault tolerance. For example, patterns have been formalized for the construction of fault tolerance solutions in the context of missioncritical infrastructure, such as telecommunication systems and space programs [Hanmer 2007]. These patterns are intended to offer solutions that meet the stringent reliability requirements of these applications. Fault tolerance patterns that are applicable more generally to various distributed system architectures have also been documented [Saridakis 2002]. These patterns are designed to handle service outages due to crash failures, byzantine failures, omission failures as well as performance failures in distributed systems. Fault tolerance patterns have also been developed in the context of distributed object computing middleware such as CORBA [Object Management Group 2012]. These patterns provide support for a range of strategies, including request retry, redirection to an alternative server, passive (primary/backup) replication, and active replication for distributed systems being developed using the standard services and protocols defined by the CORBA standard. While some of the patterns developed for distributed systems are also applicable to HPC systems, certain error and failure modes are unique to HPC environments. The design patterns and pattern language presented in this paper are designed to engineer solutions for HPC environments and focus on optimizing the balance between performance, power and resilience.

\section{SUMMARY}

The goal of HPC resilience solutions is to enable effective and resource-efficient use of computing systems at extreme scale in the presence of frequent system degradations and failures. With a new generation of large, heterogeneous HPC systems with multicomponent software environments, the complexity of the system and the interactions between the hardware and software components makes the process of protecting HPC applications from faults and their consequences extremely difficult. To navigate this complex landscape, resilience design patterns provide HPC architects and designers with a set of well-known techniques, formatted as patterns, for confronting faults in HPC systems. In this paper, we present a pattern language that reveals the relations among the resilience design patterns and provides a discipline for combining the patterns into complete, working solutions. The resilience design patterns, and the way they are organized into a pattern language, define a structured approach for architecting practical HPC resilience solutions that address the challenges of extreme rates of fault, error and failures in future HPC systems.

\section{ACKNOWLEDGMENTS}

This material is based upon work supported by the U.S. Department of Energy, Office of Science, Office of Advanced Scientific Computing Research, program manager Lucy Nowell, under contract number DE-AC05-00OR22725. We thank our shepherd Klaus Marquardt for his comments and suggestions that greatly improved the manuscript.

\section{REFERENCES}

Wesley Bland, Aurelien Bouteiller, Thomas Herault, George Bosilca, and Jack Dongarra. 2013. Post-failure recovery of MPI communication capability: Design and rationale. International Journal of High Performance Computing Applications 27, 3 (2013), 244-254.

Jinsuk Chung, Ikhwan Lee, Michael Sullivan, Jee Ho Ryoo, Dong Wan Kim, Doe Hyun Yoon, Larry Kaplan, and Mattan Erez. 2012. Containment domains: a scalable, efficient, and flexible resilience scheme for exascale systems. In Proceedings of the International Conference on High Performance Computing, Networking, Storage and Analysis. 58:1-58:11. 
Nathan DeBardeleben, James Laros, John T Daly, Stephen L Scott, Christian Engelmann, and Bill Harrod. 2009. High-end computing resilience: Analysis of issues facing the HEC community and path-forward for research and development. Whitepaper (December 2009).

Timothy J. Dell. 1997. A white paper on the benefits of chipkill-correct ECC for PC server main memory. Technical Report. IBM Microelectronics Division.

Jack Dongarra, Pete Beckman, Terry Moore, Patrick Aerts, Giovanni Aloisio, Jean-Claude Andre, David Barkai, Jean-Yves Berthou, Taisuke Boku, Bertrand Braunschweig, Franck Cappello, Barbara Chapman, Xuebin Chi, Alok Choudhary, Sudip Dosanjh, Thom Dunning, Sandro Fiore, Al Geist, Bill Gropp, Robert Harrison, Mark Hereld, Michael Heroux, Adolfy Hoisie, Koh Hotta, Zhong Jin, Yutaka Ishikawa, Fred Johnson, Sanjay Kale, Richard Kenway, David Keyes, Bill Kramer, Jesus Labarta, Alain Lichnewsky, Thomas Lippert, Bob Lucas, Barney Maccabe, Satoshi Matsuoka, Paul Messina, Peter Michielse, Bernd Mohr, Matthias S. Mueller, Wolfgang E. Nagel, Hiroshi Nakashima, Michael E Papka, Dan Reed, Mitsuhisa Sato, Ed Seidel, John Shalf, David Skinner, Marc Snir, Thomas Sterling, Rick Stevens, Fred Streitz, Bob Sugar, Shinji Sumimoto, William Tang, John Taylor, Rajeev Thakur, Anne Trefethen, Mateo Valero, Aad Van Der Steen, Jeffrey Vetter, Peg Williams, Robert Wisniewski, and Kathy Yelick. 2011. The International Exascale Software Project Roadmap. International Journal on High Performance Computing Applications (February 2011), 3-60.

E.N. (Mootaz) Elnozahy, Ricardo Bianchini, Tarek El-Ghazawi, Armando Fox, Adolfy Godfrey, Forest Hoisie, Kathryn McKinley, Rami Melhem, James Plank, Partha Ranganathan, and Josh Simons. 2010. System Resilience at Extreme Scale. Whitepaper (2010).

Robert Hanmer. 2007. Patterns for Fault Tolerant Software. Wiley Publishing.

Kuang-Hua Huang and J. A. Abraham. 1984. Algorithm-Based Fault Tolerance for Matrix Operations. IEEE Trans. Comput. C-33, 6 (June 1984), 518-528.

Saurabh Hukerikar and Christian Engelmann. 2016. Resilience Design Patterns: A Structured Approach to Resilience at Extreme Scale (Version 1.1). Technical Report ORNL/TM-2016/767. Oak Ridge National Laboratory, Oak Ridge, TN, USA.

Saurabh Hukerikar and Christian Engelmann. 2017. Resilience Design Patterns: A Structured Approach to Resilience at Extreme Scale. Supercomputing Frontiers and Innovations 4, 3 (2017), 1-38.

Cray Inc. 2014. Cray XC40 computing platform. (2014). http://www.cray.com/Assets/PDF/products/xc/CrayXC40Brochure.pdf

Peter Kogge, Keren Bergman, Shekhar Borkar, Dan Campbell, William Carlson, William Dallya, Monty Denneau, Paul Franzon, William Harrod, Kerry Hill, Jon Hiller, Sherman Karp, Stephen Keckler, Dean Klein, Robert Lucas, Mark Richards, Al Scarpelli, Steven Scott, Allan Snavely, Thomas Sterling, R. Stanley Williams, and Katherine Yelick. 2008. ExaScale Computing Study: Technology Challenges in Achieving Exascale Systems. Technical Report. DARPA.

Kathryn Mohror, Adam Moody, Greg Bronevetsky, and Bronis R. de Supinski. 2013. Detailed Modeling and Evaluation of a Scalable Multilevel Checkpointing System. IEEE Transactions on Parallel and Distributed Systems 99 (2013), 1.

Object Management Group. 2012. Common Object Request Broker Architecture (CORBA) Specification, Version 3.3. (2012). http://www.omg.org/spec/CORBA/3.3/

Titos Saridakis. 2002. A System of Patterns for Fault Tolerance. In Proceedings of 2002 European Conference on Pattern Languages of Programs (EuroPLoP). 